\title{
Associations between circulating adipokines and bone mineral density in patients with knee osteoarthritis: a cross- sectional study
}

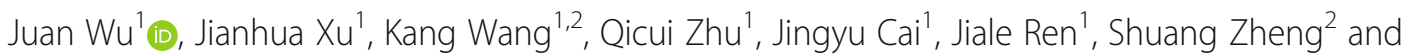
Changhai Ding ${ }^{1,2,3^{*}}$

\begin{abstract}
Background: Associations between adipokines and bone mineral density (BMD) in knee osteoarthritis (OA) remain indistinct. The aim of this study was to investigate the cross-sectional associations between serum levels of adipokines and BMD in patients with knee OA.

Methods: This study included 164 patients with symptomatic knee OA from the Anhui Osteoarthritis study. Serum levels of leptin, adiponectin, and resistin were measured using an enzyme-linked immunosorbent assay (ELISA). BMD at total body, spine, hip, and femur were measured by dual-energy X-ray absorptiometry (DXA).

Results: In multivariable analyses, serum levels of leptin were significantly associated with reduced BMD at total body, hip, total femur, femoral neck, and femoral shaft $(\beta=-0.019,95 \% \mathrm{Cl}-0.034$ to $-0.005 ; \beta=-0.018,95 \% \mathrm{Cl}-0.034$ to -0 . $003 ; \beta=-0.018,95 \% \mathrm{Cl}-0.034$ to $-0.002 ; \beta=-0.016,95 \% \mathrm{Cl}-0.032$ to $0.000 ; \beta=-0.026,95 \% \mathrm{Cl}-0.046$ to -0.006 ; respectively). Serum levels of adiponectin were significantly and negatively associated with BMD at total femur and femoral shaft ( $\beta=-0.007,95 \% \mathrm{Cl}-0.013$ to $0.000 ; \beta=-0.011,95 \% \mathrm{Cl}-0.018$ to -0.003 ; respectively). However, no significant associations were found between serum levels of resistin and BMD at any site measured.
\end{abstract}

Conclusions: Serum levels of leptin and adiponectin were significantly and negatively associated with BMD, suggesting potentially detrimental effects of leptin and adiponectin on BMD in knee OA patients.

Keywords: Adiponectin, Bone mineral density, Leptin, Osteoarthritis, Resistin

\section{Background}

Osteoarthritis $(\mathrm{OA})$ is the most prevalent joint disease worldwide, characterized by gradual loss of articular cartilage, synovial inflammation, osteophyte formation, and other structural changes. OA affected approximately $18 \%$ of women and $10 \%$ of men aged over 60 years according to the WHO's report [1].

Obesity is a well-recognized risk factor for OA, particularly in the weight-bearing joints. However,

\footnotetext{
* Correspondence: changhai.ding@utas.edu.au

'Department of Rheumatology and Immunology, Arthritis Research Institute, the First Affiliated Hospital of Anhui Medical University, 218 Jixi Street, Hefei, China

${ }^{2}$ Menzies Institute for Medical Research, University of Tasmania, Private Bag 23, Hobart, TAS 7000, Australia

Full list of author information is available at the end of the article
}

obesity-increased joint loading could not account for the associations between $\mathrm{OA}$ and non-weight-bearing joints such as hand and shoulder joints. Recent studies considered that obesity-related metabolic inflammation might contribute to OA $[2,3]$.

Adipokines, including leptin, adiponectin, and resistin which are mostly studied, are secreted by white adipose tissue, and have been found in synovial fluid and cartilage tissues obtained from OA patients [4,5]. Leptin had been shown to be positively associated with the severity of OA [6, 7]; however, leptin was significantly associated with increased knee cartilage volume in patients with radiographic OA [8]. Another study [9] reported that leptin was not significantly associated with cartilage damage in OA patients. The role of adiponectin in OA 
remains inconclusive. Some studies suggested a protective effect of adiponectin in OA $[8,10,11]$, while others found no association $[12,13]$ or even a positive association between serum adiponectin and disease severity in knee OA [14]. Studies regarding correlations between resistin and $\mathrm{OA}$ are sparse and have been controversial $[15,16]$.

The relationship between OA and bone mineral density (BMD) has been reported in various cross-sectional and longitudinal studies, but remains controversial. Previous studies revealed that higher BMD was associated with an increased risk of incident OA defined by osteophyte or Kellgren-Lawrence (KL) grade, suggesting that increased BMD was a risk factor for OA [17-19], but a recent study using MRI reported a positive association between systemic and subchondral BMD and cartilage thickness in patients with radiographic OA, indicating that BMD may play a protective role in OA [20].

Given that both adipokines and BMD might be involved in the etiology of OA, they would have a close relationship; however, associations between adipokines and BMD in OA are rarely reported though numerous studies reported the associations between adipokines and BMD in healthy human which remains controversial. One study was conducted in 60 postmenopausal women with hip or knee OA and reported no correlation between leptin and BMD [21]. Another study found that whole body BMD was positively correlated with the serum leptin level in 50 postmenopausal women with knee OA, but the correlation disappeared after adjustment for covariates [22]. To the best of our knowledge, there were no studies reporting the associations between adiponectin, resistin and BMD in OA patients so far. The aim of this study, therefore, was to investigate the cross-sectional associations between serum adipokines levels and BMD in patients with knee OA.

\section{Methods \\ Subjects}

This study was part of the Anhui Osteoarthritis (AHOA) Study, a clinical study of 205 patients aged 34-74 years, aimed to identify the environmental and biochemical factors associated with the progression of knee OA. Patients with clinical knee OA, diagnosed using American College of Rheumatology criteria [23], were consecutively recruited from the Department of Rheumatology and Immunology in the First Affiliated Hospital of Anhui Medical University, from January 2012 to November 2013. We excluded institutionalized patients, patients with rheumatoid arthritis or other inflammatory diseases, patients with severe OA planning to have knee arthroplasty in 2 years, patients who did not have blood samples so the adipokines were not able to be measured, and patients who didn't have BMD measured due to personal reasons. Forty-one patients fulfilled the exclusion criteria and therefore were excluded from this study, leaving 164 patients. The study was approved by the First Affiliated Hospital Anhui Medical University ethics committee (the ethics approval number: H1000589), and written informed consent was obtained from all participants according to the Declaration of Helsinki.

\section{Anthropometrics}

Weight was measured to the nearest $0.1 \mathrm{~kg}$ (with shoes, socks and bulky clothing removed) by using a single pair of electronic scales that were calibrated using a known weight at the beginning. Height was measured to the

Table 1 Characteristics of participants (split by median level of leptin)

\begin{tabular}{|c|c|c|c|c|}
\hline & Total $(n=164)$ & Leptin $\leq$ median $(n=82)$ & Leptin $>$ median $(n=82)$ & $p$ value \\
\hline Age, yrs ${ }^{a}$ & $55.42(8.57)$ & $54.57(8.94)$ & $56.27(8.14)$ & 0.206 \\
\hline Females, \% ${ }^{\mathrm{b}}$ & 88.4 & 81.7 & 95.1 & 0.015 \\
\hline Height, $\mathrm{cm}^{\mathrm{a}}$ & $158.64(6.83)$ & $158.62(7.70)$ & 158.66(5.90) & 0.971 \\
\hline Weight, kg ${ }^{\mathrm{a}}$ & $65.07(10.29)$ & $63.00(9.57)$ & $67.08(10.61)$ & 0.012 \\
\hline $\mathrm{BMl}, \mathrm{kg} / \mathrm{m}^{2 \mathrm{a}}$ & $25.84(3.75)$ & $24.98(2.83)$ & $26.68(4.32)$ & 0.004 \\
\hline \multicolumn{5}{|l|}{$\mathrm{BMD}, \mathrm{kg} / \mathrm{m}^{2}$} \\
\hline Total body ${ }^{a}$ & $10,55(1.22)$ & $10.64(1.41)$ & $10.46(1.02)$ & 0.361 \\
\hline Spine $^{a}$ & $10.03(1.34)$ & $10.09(1.66)$ & $9.99(1.08)$ & 0.709 \\
\hline $\mathrm{Hip}^{\mathrm{a}}$ & $8.65(1.23)$ & $8.90(1.42)$ & $8.47(1.06)$ & 0.060 \\
\hline Total femur $^{a}$ & $9.31(1.30)$ & $9.43(1.37)$ & $9.21(1.24)$ & 0.283 \\
\hline Knee ROA, \% ${ }^{\mathrm{b}}$ & 71.95 & 78.05 & 65.85 & 0.082 \\
\hline Adiponectin, ug/ml ${ }^{c}$ & $27.09(6.80,60.88)$ & $11.73(3.56,35.25)$ & $49.70(20.62,74.10)$ & $<0.001$ \\
\hline Resistin, $\mathrm{ng} / \mathrm{ml}^{c}$ & $2.22(1.40,4.55)$ & $2.06(1.17,4.39)$ & $2.27(1.48,4.63)$ & 0.327 \\
\hline
\end{tabular}

Leptin median level: $5.92 \mathrm{ng} / \mathrm{ml}$

Data in bold denote statistically significant results

$B M I$ body mass index, $B M D$ bone mineral density, $B M C$ bone mineral content, $R O A$ radiographic osteoarthritis

${ }^{a} \mathrm{t}$ tests were used for mean (standard deviation), ${ }^{b} \mathrm{x}^{2}$ tests for the proportions, ${ }^{\mathrm{C}}$ Mann-Whitney $\mathrm{U}$ tests for median (interquartile range) 
nearest $0.1 \mathrm{~cm}$ (with shoes, socks and headgear removed) by using a stadiometer. Body mass index (BMI) was calculated [weight $(\mathrm{kg}) /$ height $\left.(\mathrm{m})^{2}\right]$.

\section{Serum adipokines measurements}

Fasting blood was obtained from all patients in the morning. Serum was separated and aliquotted into plastic storage tubes. Aliquots were stored at $-80{ }^{\circ} \mathrm{C}$ till analysis. Serum levels of leptin, adiponectin, and resistin were measured by using enzyme-linked immunosorbent assay (ELISA; eBioscience, USA) kits, according to the manufacturer's instructions. The intra- and inter-assay coefficient of variations for leptin, adiponectin, and resistin were 5.7 and $6.9 \%, 4.2$ and $3.1 \%, 5.1$ and $8.1 \%$, respectively.

\section{BMD measurement}

BMD of the total body, spine, hip and total femur, including femoral neck, Wards triangle, greater trochanter, and femoral shaft were measured using dual-energy $\mathrm{x}$-ray absorptiometry (DXA) (Lunar Prodigy DF $+310,504$, GE Healthcare, USA). BMD was calculated from the bone area $\left(\mathrm{cm}^{2}\right)$ and bone mineral content $(\mathrm{g})$ and expressed in $\mathrm{g} / \mathrm{cm}^{2}$ [24]. The unit of BMD was converted to $\mathrm{kg} / \mathrm{m}^{2}$ to keep the levels of adipokines and BMD at the similar magnitudes.

\section{Knee radiographic assessment}

A standing anteroposterior semiflexed view of the diseased knee (the severer one if both were affected) with $15^{\circ}$ of fixed knee flexion, was performed in all participants. KL grading system (grades $0-4$ ) was used to assess the radiographic severity of OA [25]. Radiographic OA (ROA) was defined as KL grade of $\geq 2$.

\section{Statistical analysis}

Student's $\mathrm{t}$ tests, Mann-Whitney $\mathrm{U}$ tests or chi-squared tests were used to compare means, median or proportions, respectively. Univariable and multivariable linear regression analyses were used to examine the associations between adipokines and BMD before and after adjustment for age, sex, BMI and ROA. Scatter plots were also used to depict the associations between adipokines and BMD after adjustment for the above-mentioned covariates. Standard diagnostic checks of model fit and residuals were routinely made, and data points with large residuals and/ or high influence were investigated for data errors. A $p$ value $<0.05$ (two-tailed) or a 95\% confidence interval (CI) not including the null point was regarded as statistically significant. All statistical analyses were performed using SPSS 13.0 for Windows (SPSS, Chicago, IL, USA).

\section{Results}

A total of 164 subjects between 34 and 74 years of age (mean, $55.4 \mathrm{yrs}$ ) participated in our study. Of these, all subjects measured the BMD of total body and total femur, however, only 133 subjects measured the BMD of spine and hip. There were no significant differences in demographic factors (age, sex, and BMI) between these participants and those excluded ( $n=41$; data not shown). Characteristics of the participants are presented in Table 1. The mean BMI was $25.84 \mathrm{~kg} / \mathrm{m}^{2}$. The median levels of leptin, adiponectin, and resistin were $5.92 \mathrm{ng} / \mathrm{ml}, 27.09 \mu \mathrm{g} /$ $\mathrm{ml}$, and $2.22 \mathrm{ng} / \mathrm{ml}$, respectively. Subjects with higher and lower levels of leptin (split at the median level) were similar in age, height, BMD at all sites measured, prevalence of ROA and levels of resistin; however, subjects with higher leptin levels had greater proportion of females, higher weight, higher BMI and higher adiponectin levels.

There were no interactions between serum levels of adipokines and sex on the BMD (data not shown). Therefore, males and females were combined for analyses in our study.

Associations between leptin and BMD were shown in Table 2. In univariable analyses, we did not find any significant associations between serum levels of leptin and BMD at any site measured. However, after

Table 2 Associations between leptin and BMD in various regions

\begin{tabular}{|c|c|c|c|c|}
\hline & \multicolumn{2}{|l|}{ Univariable } & \multicolumn{2}{|l|}{ Multivariable $^{a}$} \\
\hline & $\beta(95 \% \mathrm{Cl})$ & $p$ value & $\beta(95 \% \mathrm{Cl})$ & $p$ value \\
\hline Total body BMD & $-0.011(-0.026,0.004)$ & 0.155 & $-0.019(-0.034,-0.005)$ & 0.009 \\
\hline Spine BMD & $0.004(-0.013,0.021)$ & 0.653 & $-0.010(-0.028,0.007)$ & 0.248 \\
\hline Hip BMD & $-0.010(-0.025,0.006)$ & 0.213 & $-0.018(-0.034,-0.003)$ & 0.018 \\
\hline Total femur BMD & $-0.007(-0.023,0.008)$ & 0.352 & $-0.018(-0.034,-0.002)$ & 0.024 \\
\hline Femoral neck & $-0.010(-0.025,0.006)$ & 0.218 & $-0.016(-0.032,0.000)$ & 0.048 \\
\hline Wards triangle & $-0.007(-0.025,0.011)$ & 0.462 & $-0.012(-0.029,0.006)$ & 0.194 \\
\hline Greater trochanter & $-0.004(-0.018,0.009)$ & 0.538 & $-0.013(-0.026,0.001)$ & 0.074 \\
\hline Femoral shaft & $-0.008(-0.028,0.011)$ & 0.386 & $-0.026(-0.046,-0.006)$ & 0.012 \\
\hline
\end{tabular}

Dependent variable: BMD in respective compartment

Independent variable: leptin

Data in bold denote statistically significant results

$B M D$ bone mineral density, $B M I$ body mass index, $R O A$ radiographic osteoarthritis

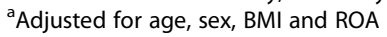



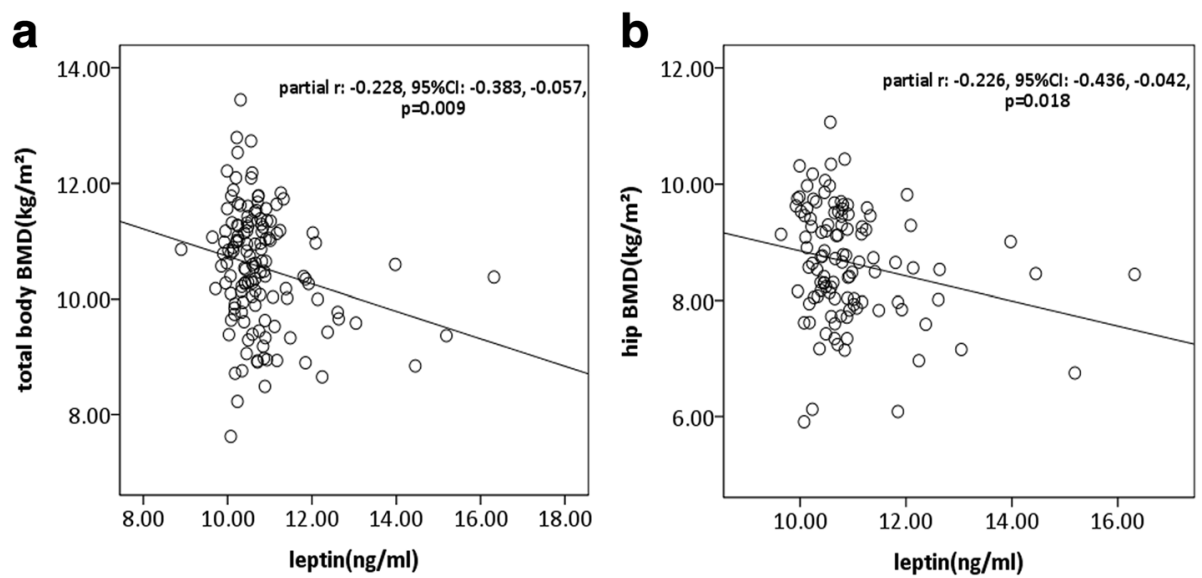

Fig. 1 Scatter plot for associations between serum levels of leptin and bone mineral density (BMD). In multivariable analyses, higher serum levels of leptin were associated with lower BMD at total body (a) and hip (b)

adjustment for age, sex, BMI and ROA, serum levels of leptin were significantly associated with reduced BMD at total body, hip, femoral neck, femoral shaft, and total femur (Table 2, Fig. 1).

Serum adiponectin was significantly and negatively associated with BMD at femoral shaft and total femur in univariable analyses. These negative associations remained unchanged after adjustment for the covariates mentioned above (Table 3, Fig. 2). We did not find any significant associations between serum adiponectin and BMD at total body, spine, and hip. The association between adiponectin and femoral neck BMD was also negative but of borderline statistical significance (Table 3).

The associations between serum resistin and BMD at any site did not reach statistical significance before and after adjustment for age, sex, BMI and ROA (Table 4).

\section{Discussion}

The present study investigated the cross-sectional associations between adipokines (including leptin, adiponectin, and resistin) and BMD in patients with knee OA. We found that the serum leptin levels were negatively associated with total body, hip and total femur (including femoral neck and femoral shaft) BMD. Serum adiponectin was also significantly associated with reduced BMD at total femur and femoral shaft. In contrast, no association was found between serum resistin and BMD.

Leptin, a protein encoded by the ob gene, was found to regulate bone metabolism. Various studies have demonstrated the association between leptin and BMD. Ducy et al. [26] found that intracerebroventricular infusion of leptin induced bone loss in both leptin-deficient and wild-type mice, suggesting that leptin could inhibit bone formation acting through the hypothalamus.

Table 3 Associations between adiponectin and BMD in various regions

\begin{tabular}{|c|c|c|c|c|}
\hline & \multicolumn{2}{|l|}{ Univariable } & \multicolumn{2}{|l|}{ Multivariable $^{a}$} \\
\hline & $\beta(95 \% \mathrm{Cl})$ & $p$ value & $\beta(95 \% \mathrm{Cl})$ & $p$ value \\
\hline Total body BMD & $-0.005(-0.010,0.000)$ & 0.072 & $-0.002(-0.007,0.003)$ & 0.432 \\
\hline Spine BMD & $-0.006(-0.013,0.002)$ & 0.123 & $-0.002(-0.010,0.005)$ & 0.518 \\
\hline Hip BMD & $-0.006(-0.012,0.001)$ & 0.100 & $-0.002(-0.009,0.004)$ & 0.456 \\
\hline Total femur BMD & $-0.006(-0.012,0.000)$ & 0.034 & $-0.007(-0.013,0.000)$ & 0.030 \\
\hline Femoral neck & $-0.006(-0.011,0.000)$ & 0.061 & $-0.005(-0.011,0.001)$ & 0.088 \\
\hline Wards triangle & $-0.005(-0.012,0.002)$ & 0.137 & $-0.004(-0.010,0.003)$ & 0.234 \\
\hline Greater trochanter & $-0.004(-0.009,0.001)$ & 0.116 & $-0.002(-0.007,0.003)$ & 0.436 \\
\hline Femoral shaft & $-0.008(-0.015,-0.001)$ & 0.025 & $-0.011(-0.018,-0.003)$ & 0.006 \\
\hline
\end{tabular}

Dependent variable: BMD in respective compartment Independent variable: adiponectin

Data in bold denote statistically significant results

$B M D$ bone mineral density, $B M I$ body mass index, $R O A$ radiographic osteoarthritis

${ }^{a}$ Adjusted for age, sex, BMI and ROA 

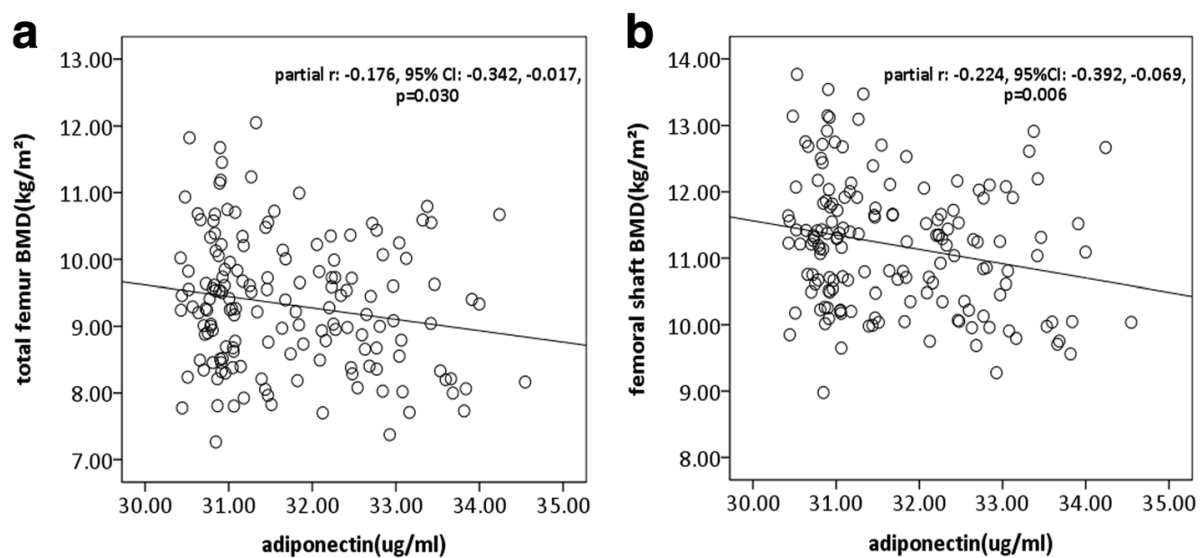

Fig. 2 Scatter plot for associations between serum levels of adiponectin and bone mineral density (BMD). In multivariable analyses, higher serum levels of adiponectin were associated with lower BMD at total femur (a) and femoral shaft (b)

Epidemiological studies reported that serum leptin concentrations were inversely associated with calcaneal BMD after adjustment for body weight in 221 healthy adult men [27], and leptin had a negative correlation with lumbar spine BMD in perimenopausal healthy women [28]. On the contrary, some studies reported a positive association between leptin and BMD. Martin et al. [29] demonstrated that peripheral administration of leptin could prevent disuse-induced bone loss through inhibiting the increase in bone resorption mediated by the RANKL/OPG and preventing the decrease in bone formation in tail-suspended female rats. Blain et al. [30] found that leptin was positively associated with whole body and femoral neck BMD in 155 postmenopausal women. Weiss et al. [31] reported that leptin predicted an increase in BMD in postmenopausal women but not older men after adjustment for age, BMI, and other bone related factors. In addition, several clinical studies reported no association between leptin and BMD or BMD change [32, 33]. It was noteworthy that these studies mentioned above were conducted in healthy persons. Only two clinical studies investigated the association between leptin and BMD in OA [21, 22] and reported inconsistent results. Our study found that serum leptin was significantly associated with reduced BMD in patients with knee OA, independent of age, sex, BMI, and ROA. This suggests that leptin may play a potentially detrimental effect on BMD in knee OA.

Adiponectin was considered to have a negative effect on bone metabolism. Adiponectin levels were negatively associated with femoral neck and total body BMD in postmenopausal women after adjustment for potential confounders [32], and highest tertile of adiponectin had significantly greater hip BMD loss than the lowest tertile of adiponectin in women [33]. A meta-analysis indicated that adiponectin was the mostly relevant adipokine that was negatively associated with BMD in healthy subjects, regardless of menopausal status and gender [34].

Table 4 Associations between resistin and BMD in various regions

\begin{tabular}{|c|c|c|c|c|}
\hline & \multicolumn{2}{|l|}{ Univariable } & \multicolumn{2}{|l|}{ Multivariable $\mathrm{e}^{\mathrm{a}}$} \\
\hline & $\beta(95 \% \mathrm{Cl})$ & $p$ value & $\beta(95 \% \mathrm{Cl})$ & $p$ value \\
\hline Total body BMD & $0.005(-0.042,0.053)$ & 0.825 & $0.005(-0.037,0.048)$ & 0.801 \\
\hline Spine BMD & $-0.022(-0.117,0.072)$ & 0.639 & $-0.024(-0.120,0.071)$ & 0.612 \\
\hline Hip BMD & $-0.005(-0.093,0.083)$ & 0.913 & $0.012(-0.072,0.096)$ & 0.777 \\
\hline Total femur BMD & $-0.010(-0.061,0.042)$ & 0.712 & $-0.007(-0.056,0.043)$ & 0.792 \\
\hline Femoral neck & $-0.023(-0.075,0.029)$ & 0.376 & $-0.023(-0.073,0.027)$ & 0.358 \\
\hline Wards triangle & $-0.030(-0.090,0.030)$ & 0.327 & $-0.031(-0.086,0.023)$ & 0.257 \\
\hline Greater trochanter & $-0.014(-0.059,0.031)$ & 0.528 & $-0.012(-0.054,0.030)$ & 0.568 \\
\hline Femoral shaft & $0.002(-0.062,0.066)$ & 0.951 & $0.003(-0.061,0.067)$ & 0.918 \\
\hline
\end{tabular}

Dependent variable: BMD in respective compartment

Independent variable: resistin

$B M D$ bone mineral density, $B M I$ body mass index, $R O A$ radiographic osteoarthritis

${ }^{a}$ Adjusted for age, sex, BMI and ROA 
Oshima et al. [35] reported that adiponectin supplement increased bone mass in trabecular bone via inhibiting osteoclast and activating osteoblast. In contrast, Kontogianni et al. [28] found no associations between adiponectin and lumber spine BMD in perimenopausal women, and Barbour et al. [33] found adiponectin levels were not correlated with whole-body areal BMD or trabecular lumbar spine volumetric BMD loss in older women and men. Our current study is the first to investigate the association between adiponectin and BMD in patients with knee $\mathrm{OA}$, indicating a potentially detrimental effect of adiponectin on BMD in knee OA.

Serum leptin levels are positively correlated with BMI, while serum adiponectin levels are negatively correlated with BMI [36]. However, we found that both serum levels of leptin and adiponectin were negatively associated with BMD in OA. The potential mechanism is unclear, and it needs to be further investigated.

So far, there are a few studies reporting the association between resistin and BMD. Serum resistin was not associated with BMD of total body, lumbar spine, and total hip before and after adjustment for age and fat mass in 232 Chinese men [37], and was not an independent predictor of BMD in 336 healthy postmenopausal Chinese women aged 41-81 years [38]. One study reported that serum resistin levels were significantly and negatively associated with lumbar spine BMD in 80 middle-aged men [39]. In our current study, we didn't find any significant association between serum resistin and BMD in patients with knee OA.

There are several limitations in our study. First, due to the cross-sectional nature, the causality between adipokines and BMD is not able to be determined. Further longitudinal studies are needed to verify our findings. Second, the sample size was modest. This may be the reason why we did not find significant association between resistin and BMD. Third, 41 patients were excluded from this study which may cause selection bias; however, there were no significant differences in age, sex, and BMI between patients who were included and excluded. Last, there would be variations in muscle and fat mass which may affect the associations; however, the results remained largely unchanged after the adjustment for muscle or fat mass.

\section{Conclusions}

Serum leptin and adiponectin levels were significantly and negatively associated with BMD, suggesting potentially detrimental effects of leptin and adiponectin on BMD in knee OA patients.

\section{Abbreviations}

BMD: Bone mineral density; BMI: Body mass index; Cl: Confidence interval; DXA: Dual-energy X-ray absorptiometry; ELISA: Enzyme-linked immunosorbent assay; KL: Kellgren-Lawrence; OA: Osteoarthritis; ROA: Radiographic OA

\section{Acknowledgments}

We would like to thank the participants who made this study possible, and thank the staff and volunteers who collected the data.

\section{Funding}

This study was supported by the National Natural Science Foundation of China (81172865).

\section{Availability of data and materials}

The datasets used and analysed during the current study are available from the corresponding author on reasonable request.

\section{Authors' contributions}

Study conception and design: CD and JX. Acquisition of data: JW, KW, QZ, JC, JR and SZ. Analysis and interpretation of data: JW and CD. Drafting of the article: JW and CD. Revising and final approval of the article: All authors.

\section{Ethics approval and consent to participate}

The study was approved by the First Affiliated Hospital Anhui Medical University ethics committee (the ethics approval number: H1000589), and written informed consent was obtained from all participants according to the Declaration of Helsinki.

\section{Consent for publication}

Not applicable.

\section{Competing interests}

The authors declare that they have no competing interests. Changhai Ding is a Deputy Section Editor of BMC Musculoskeletal Disorders.

\section{Publisher's Note}

Springer Nature remains neutral with regard to jurisdictional claims in published maps and institutional affiliations.

\section{Author details}

'Department of Rheumatology and Immunology, Arthritis Research Institute, the First Affiliated Hospital of Anhui Medical University, 218 Jixi Street, Hefei, China. ${ }^{2}$ Menzies Institute for Medical Research, University of Tasmania, Private Bag 23, Hobart, TAS 7000, Australia. ${ }^{3}$ Institute of Bone \& Joint Translational Research, Southern Medical University, Guangzhou, Guangdong, China.

Received: 12 August 2017 Accepted: 11 January 2018

Published online: 17 January 2018

\section{References}

1. Woolf AD, Pfleger B. Burden of major musculoskeletal conditions. Bull World Health Organ. 2003;81:646-56.

2. Sowers MR, Karvonen-Gutierrez CA. The evolving role of obesity in knee osteoarthritis. Curr Opin Rheumatol. 2010;22:533-7.

3. Wang $X$, Hunter $D, X u$ J, Ding $C$. Metabolic triggered inflammation in osteoarthritis. Osteoarthr Cartil. 2015;23:22-30.

4. Presle N, Pottie P, Dumond H, Guillaume C, Lapicque F, Pallu S, et al. Differential distribution of adipokines between serum and synovial fluid in patients with osteoarthritis. Contribution of joint tissues to their articular production. Osteoarthr Cartil. 2006;14:690-5.

5. Francin PJ, Abot A, Guillaume C, Moulin D, Bianchi A, Gegout-Pottie P, et al. Association between adiponectin and cartilage degradation in human osteoarthritis. Osteoarthr Cartil. 2014;22:519-26.

6. Stannus OP, Jones G, Quinn SJ, Cicuttini FM, Dore D, Ding C. The association between leptin, interleukin-6, and hip radiographic osteoarthritis in older people: a cross-sectional study. Arthritis Res Ther. 2010;12:R95.

7. Staikos C, Ververidis A, Drosos G, Manolopoulos VG, Verettas DA, Tavridou A. The association of adipokine levels in plasma and synovial fluid with the severity of knee osteoarthritis. Rheumatology (Oxford). 2013;52:1077-83.

8. Zheng $S, X u J, X u S$, Zhang M, Huang $S$, He F, et al. Association between circulating adipokines, radiographic changes, and knee cartilage volume in patients with knee osteoarthritis. Scand J Rheumatol. 2016;45:224-9.

9. de Boer TN, van Spil WE, Huisman AM, Polak AA, Biilsma JW, Lafeber FP, et al. Serum adipokines in osteoarthritis; comparison with controls and relationship with local parameters of synovial inflammation and cartilage damage. Osteoarthr Cartil. 2012;20:846-53. 
10. Honsawek S, Chayanupatkul M. Correlation of plasma and synovial fluid adiponectin with knee osteoarthritis severity. Arch Med Res. 2010;41:593-8.

11. Yusuf E, loan-Facsinay A, Bijsterbosch J, Klein-Wieringa I, Kwekkeboom J, Slagboom PE, et al. Association between leptin, adiponectin and resistin and long-term progression of hand osteoarthritis. Ann Rheum Dis. 2011; 70:1282-4.

12. Berry PA, Jones SW, Cicuttini FM, Wluka AE, Maciewicz RA. Temporal relationship between serum adipokines, biomarkers of bone and cartilage turnover, and cartilage volume loss in a population with clinical knee osteoarthritis. Arthritis Rheum. 2011;63:700-7.

13. Massengale M, Lu B, Pan JJ, Katz JN, Solomon DH. Adipokine hormones and hand osteoarthritis: radiographic severity and pain. PLoS One. 2012; 7:e47860.

14. Cuzdan Coskun N, Ay S, Evcik FD, Oztuna D. Adiponectin: is it a biomarker for assessing the disease severity in knee osteoarthritis patients? Int J Rheum Dis. 2015;6 [Epub ahead of print]

15. Koskinen A, Vuolteenaho K, Moilanen T, Moilanen E. Resistin as a factor in osteoarthritis: synovial fluid resistin concentrations correlate positively with interleukin 6 and matrix metalloproteinases MMP-1 and MMP-3. Scand J Rheumatol. 2014;43:249-53.

16. Martel-Pelletier J, Raynauld JP, Dorais M, Abram F, Pelletier JP. The levels of the adipokines adipsin and leptin are associated with knee osteoarthritis progression as assessed by MRI and incidence of total knee replacement in symptomatic osteoarthritis patients: a post hoc analysis. Rheumatology (Oxford). 2016;55:680-8.

17. Zhang Y, Hannan MT, Chaisson CE, McAlindon TE, Evans SR, Aliabadi P, et al. Bone mineral density and risk of incident and progressive radiographic knee osteoarthritis in women: the Framingham study. J Rheumatol. 2000;27:1032-7.

18. Hochberg MC, Lethbridge-Cejku M, Tobin JD. Bone mineral density and osteoarthritis: data from the Baltimore longitudinal study of aging. Osteoarthr Cartil. 2004;12(Suppl A):S45-8.

19. Hart DJ, Cronin C, Daniels M, Worthy T, Doyle DV, Spector TD. The relationship of bone density and fracture to incident and progressive radiographic osteoarthritis of the knee: the Chingford study. Arthritis Rheum. 2002:46:92-9.

20. Cao Y, Stannus OP, Aitken D, Cicuttini F, Antony B, Jones G, et al. Crosssectional and longitudinal associations between systemic, subchondral bone mineral density and knee cartilage thickness in older adults with or without radiographic osteoarthritis. Ann Rheum Dis. 2014;73:2003-9.

21. Jiang LS, Zhang ZM, Jiang SD, Chen WH, Dai LY. Differential bone metabolism between postmenopausal women with osteoarthritis and osteoporosis. J Bone Miner Res. 2008:23:475-83.

22. Iwamoto J, Takeda T, Sato Y, Matsumoto H. Serum leptin concentration positively correlates with body weight and total fat mass in postmenopausal Japanese women with osteoarthritis of the knee. Arthritis. 2011;2011:580632

23. Altman RD. The classification of osteoarthritis. J Rheumatol Suppl 1995:43:42-3.

24. Xu S, Ma XX, Hu LW, Peng LP, Pan FM, Xu JH. Single nucleotide polymorphism of RANKL and OPG genes may play a role in bone and joint injury in rheumatoid arthritis. Clin Exp Rheumatol. 2014;32:697-704.

25. Kellgren JH, Lawrence JS. Radiological assessment of osteoarthrosis. Ann Rheum Dis. 1957;16:494-502.

26. Ducy P, Amling M, Takeda S, Priemel M, Schilling AF, Beil FT, et al. Leptin inhibits bone formation through a hypothalamic relay: a central control of bone mass. Cell. 2000;100:197-207.

27. Sato M, Takeda N, Sarui H, Takami R, Takami K, Hayashi M, et al. Association between serum leptin concentrations and bone mineral density, and biochemical markers of bone turnover in adult men. J Clin Endocrinol Metab. 2001;86:5273-6.

28. Kontogianni MD, Dafni UG, Routsias JG, Skopouli FN. Blood leptin and adiponectin as possible mediators of the relation between fat mass and BMD in perimenopausal women. J Bone Miner Res. 2004;19:546-51.

29. Martin A, de Vittoris R, David V, Moraes R, Bégeot M, Lafage-Proust MH, et al. Leptin modulates both resorption and formation while preventing disuse-induced bone loss in tail-suspended female rats. Endocrinology. 2005; 146:3652-9.

30. Blain H, Vuillemin A, Guillemin F, Durant R, Hanesse B, de Talance N, et al. Serum leptin level is a predictor of bone mineral density in postmenopausal women. J Clin Endocrinol Meta. 2002;87:1030-5.
31. Weiss LA, Barrett-Connor E, von Mühlen D, Clark P. Leptin predicts BMD and bone resorption in older women but not older men: the rancho Bernardo study. J Bone Miner Res. 2006;21:758-64.

32. Värri $M$, Niskanen $L$, Tuomainen $T$, Honkanen $R$, Kröger $H$, Tuppurainen MT. Association of adipokines and estradiol with bone and carotid calcifications in postmenopausal women. Climacteric. 2016;19:204-11.

33. Barbour KE, Zmuda JM, Boudreau R, Strotmeyer ES, Horwitz MJ, Evans RW, et al. The effects of adiponectin and leptin on changes in bone mineral density. Osteoporos Int. 2012;23:1699-710.

34. Biver E, Salliot C, Combescure C, Gossec L, Hardouin P, Legroux-Gerot I, et al. Influence of adipokines and ghrelin on bone mineral density and fracture risk: a systematic review and meta-analysis. J Clin Endocrinol Metab. 2011; 96:2703-13.

35. Oshima K, Nampei A, Matsuda M, Iwaki M, Fukuhara A, Hashimoto J, et al. Adiponectin increases bone mass by suppressing osteoclast and activating osteoblast. Biochem Biophys Res Commun. 2005;331:520-6.

36. Poonpet T, Honsawek S. Adipokines: biomarkers for osteoarthritis? World J Orthop. 2014;5:319-27.

37. Peng XD, Xie H, Zhao Q, Wu XP, Sun ZQ, Liao EY. Relationships between serum adiponectin, leptin, resistin, visfatin levels and bone mineral density, and bone biochemical markers in Chinese men. Clin Chim Acta. 2008;387:31-5.

38. Zhang H, Xie H, Zhao Q, Xie GQ, Wu XP, Liao EY, et al. Relationships between serum adiponectin, apelin, leptin, resistin, visfatin levels and bone mineral density, and bone biochemical markers in post-menopausal Chinese women. J Endocrinol Investig. 2010;33:707-11.

39. Oh KW, Lee WY, Rhee EJ, Baek KH, Yoon KH, Kang MI, et al. The relationship between serum resistin, leptin, adiponectin, ghrelin levels and bone mineral density in middle-aged men. Clin Endocrinol. 2005;63:131-8.

\section{Submit your next manuscript to BioMed Central and we will help you at every step:}

- We accept pre-submission inquiries

- Our selector tool helps you to find the most relevant journal

- We provide round the clock customer support

- Convenient online submission

- Thorough peer review

- Inclusion in PubMed and all major indexing services

- Maximum visibility for your research

Submit your manuscript at www.biomedcentral.com/submit

) Biomed Central 